\begin{tabular}{|c|c|c|c|}
\hline \multirow{3}{*}{$\begin{array}{r}\text { Case Reports in } \\
\text { Gastroenterology }\end{array}$} & Case Rep Gastroenterol 2016; & & \multirow[b]{2}{*}{$\begin{array}{l}\text { Karger } \\
\text { Open access }\end{array}$} \\
\hline & $\begin{array}{l}\text { DOI: } 10.1159 / 000448883 \\
\text { Published online: September 12, } 2016\end{array}$ & $\begin{array}{l}\text { (c) } 2016 \text { The Author(s) } \\
\text { Published by S. Karger AG, Basel } \\
\text { www.karger.com/crg }\end{array}$ & \\
\hline & $\begin{array}{l}\text { This article is licensed under the } \mathrm{Cr} \\
\text { International License (CC BY-NC) (ht } \\
\text { Usage and distribution for commercial }\end{array}$ & $\begin{array}{l}\text { mons Attribution-NonCommercial } 4 . \\
\text { ger.com/Services/OpenAccessLicense } \\
\text { uires written permission. }\end{array}$ & \\
\hline
\end{tabular}

\title{
The Diagnosis and Manifestations of Liver Injury Secondary to Off-Label Androgenic Anabolic Steroid Use
}

\author{
Elena Cabb ${ }^{a}$ Shanna Baltar ${ }^{a}$ David Wes Powers ${ }^{b}$ Karthik Mohan ${ }^{b}$ \\ Antonio Martinez ${ }^{c}$ Eric Pitts ${ }^{a}$ \\ ${ }^{a}$ Department of Graduate Medical Education, NSU-COM/Palmetto General Hospital, \\ Hialeah, Fla., USA; ${ }^{b}$ Gastroenterology Department, NSU-COM/Larkin Community Hospital, \\ South Miami, Fla., USA; 'Department of Pathology, Palmetto General Hospital, \\ Hialeah, Fla., USA
}

\section{Keywords}

Liver injury · Androgenic anabolic steroids · Histopathology

\begin{abstract}
Drug-induced liver injury (DILI) presents as a broad spectrum of adverse drug reactions which can range from a mild elevation in liver enzymes to fulminant liver failure. The primary goal is to identify DILI early when the patient's liver enzymes are elevated and to discontinue the offending agent as soon as possible to prevent further injury. Herbal, dietary supplements and anabolic steroids represent a significant component of the drugs thought to cause DILI in the United States. Unlike all other drugs known to cause DILI, these drugs fall into a category of injury that is neither intrinsic nor idiosyncratic due to overlapping characteristics between the two. Here, we present a case of the off-label use of androgenic anabolic steroids inducing liver injury. A combination of clinical, laboratory, and histologic workup eventually led to the diagnosis of DILI. This can be a diagnostic challenge for practitioners. The American College of Gastroenterology (ACG) published guidelines to aid the clinician in diagnosing DILI. Proving that an episode of liver injury is caused by a drug is difficult in many cases as it requires the exclusion of alternative etiologies. Some of the variables include temporal association, clinical-biochemical features, type of injury (hepatocellular and/or cholestatic), extrahepatic features, and the likelihood that a given agent is the culprit based on its known manifestations with prior cases. This case illustrates the utility of the diagnostic tools
\end{abstract}




\section{Case Reports in Gastroenterology}

Case Rep Gastroenterol 2016;10:499-505 DOI: $10.1159 / 000448883$

(C) 2016 The Author(s). Published by S. Karger AG, Basel www.karger.com/crg

Cabb et al.: The Diagnosis and Manifestations of Liver Injury Secondary to Off-Label Androgenic Anabolic Steroid Use

used for DILI as recommended by the ACG, along with a supplemental histopathologic diagnosis.

\section{Introduction}

Drug-induced liver injury (DILI) presents as a broad spectrum of adverse drug reactions which can range from mild elevation in liver enzymes to fulminant liver failure. It is considered the most common cause of death from acute liver failure in the United States [1]. Due to the highly variable clinical spectrum of DILI, it may be difficult to identify and therefore is a diagnosis of exclusion. In 2014, the American College of Gastroenterology (ACG) published guidelines to aid the clinician in diagnosing and treating DILI. The primary goal is to identify DILI early when the patient's liver enzymes are elevated and to discontinue the offending agent as soon as possible to prevent further injury. Though challenging, early identification of DILI is vital to prevent higher morbidity and mortality associated with delayed diagnosis.

It is important to note that DILI is characterized into intrinsic (toxic) and idiosyncratic types, with the latter being much rarer [2]. This is perhaps due to the higher incidence of acetaminophen-induced intrinsic reactions compared to drugs known to cause idiosyncratic reactions (i.e., antibiotics and antiepileptics) [2, 3]. In the past, viral hepatitis was the main culprit in acute liver failure, though recent prospective studies indicate that drugs are now the most common cause [4]. Further adding to the complication of diagnosis is the fact that liver injury seen with viral hepatitis may resemble the morphology of idiosyncratic DILI [5].

Herbal, dietary supplements and anabolic steroids represent a significant component of the drugs thought to cause DILI in the United States [6]. However, unlike all other drug categories known to cause DILI, these drugs fall into a category of injury that is neither intrinsic nor idiosyncratic due to overlapping characteristics between the two. Here, we present a case of the off-label use of androgenic anabolic steroids (AAS) inducing liver injury.

\section{Case Report}

A 45-year-old male with no significant past medical history presented to the hospital complaining of progressive pruritus, jaundice, and scleral icterus for the past 2 weeks. His associated signs included pale stools and dark urine. He denied change in activity, recent travel, fever, malaise, upper respiratory symptoms, or sick contacts. He had no anorexia, weight loss, abdominal pain, nausea, or vomiting. The patient denied tobacco, ethanol, or illicit drug use. However, he admitted to having taken steroids for the past 3 months (Anavar $50 \mathrm{mg}$ daily and testosterone injections once weekly) but discontinued after the onset of symptoms.

On presentation, the patient was normotensive, afebrile, and in no acute distress. His physical exam was remarkable for scleral icterus, a minimally tender right upper quadrant, and slight jaundice. He had no signs of a rash, hepatosplenomegaly, tremors, edema, ascites, spider angioma, jugular venous distension, or neurological deficits. Murphy's or Courvoisier sign were not appreciated.

Laboratory studies revealed alkaline phosphatase $262 \mathrm{IU} / \mathrm{l}$, total bilirubin $4.95 \mathrm{mg} / \mathrm{dl}$, direct bilirubin $3.8 \mathrm{mg} / \mathrm{dl}$, indirect bilirubin $1.2 \mathrm{mg} / \mathrm{dl}$, alanine aminotransferase $162 \mathrm{IU} / \mathrm{l}$, aspartate aminotransferase $72 \mathrm{IU} / \mathrm{l}$, and lipase $160 \mathrm{IU} / \mathrm{l}$. A computed tomography (CT) of the abdomen and pelvis with contrast showed a slight prominence of the pancreatic head, 
which may have been normal for the patient's age. There were no definite masses or biliary dilatation. There was a questionable small $1-$ to $2-\mathrm{mm}$ gallstone versus a tiny gallbladder polyp on ultrasonography of the abdomen, and the liver appeared unremarkable in this study. A magnetic resonance cholangiopancreatography was performed to better assess the biliary tree and pancreas. It also revealed a normal liver without masses, along with an unremarkable spleen, adrenal glands, and kidneys. In concurrence with the CT of the abdomen, a mild prominence of the head of the pancreas was seen without evidence of a mass. The intra- and extrahepatic biliary tree was without evidence of choledocolithiasis, and pancreatic ducts were unremarkable. No definite filling defects of the gallbladder were visualized.

Esophagogastroduodenoscopy revealed a small clean-based ulcer in the gastric body and a normal duodenum. Endoscopic ultrasound was then performed showing a homogenous left lobe of the liver and mild fatty infiltration without mass lesions. The body of the pancreas was visualized and normal in appearance, the pancreatic duct was nondilated, and the pancreatic body and tail were without masses or cysts. The common bile duct was without dilatation, and there was no evidence of choledocholithiasis. The gallbladder was mildly contracted with a 3-mm gallstone.

Histological findings from the ultrasound-guided nontargeted liver biopsy revealed mild portal chronic inflammation with few eosinophils, a few early ill-defined portal granulomas, centrilobular hepatocyte dropout (fig. 3) with scattered councilman bodies, and mild pericentral vein cholestasis (fig. 2).

Throughout the hospital course, the patient's laboratory studies remained stable with slight undulation in total bilirubin. Serology testing for acute Epstein-Barr virus and cytomegalovirus infection, acute viral hepatitis, HIV, herpes simplex virus, various autoimmune diseases, and tumor markers (CEA, CA 19-9, AFP) was negative. The patient was subsequently discharged home and directed to follow-up with the gastroenterologist as an outpatient. He had two follow-up visits where a complete metabolic panel was repeated. The first visit, 4 days after hospital discharge, showed worsening laboratory values, although the patient's overall history and physical examination expressed clinical improvement: alkaline phosphatase $286 \mathrm{IU} / \mathrm{l}$, total bilirubin $6.4 \mathrm{mg} / \mathrm{dl}$, alanine aminotransferase $67 \mathrm{IU} / \mathrm{l}$, and aspartate aminotransferase $46 \mathrm{IU} / \mathrm{l}$. The second visit, 12 days after hospital discharge, showed improving laboratory values along with the patient's overall history and physical examination, expressing continued clinical improvement: alkaline phosphatase $259 \mathrm{IU} / \mathrm{l}$, total bilirubin $3.0 \mathrm{mg} / \mathrm{dl}$, alanine aminotransferase $66 \mathrm{IU} / \mathrm{l}$, and aspartate aminotransferase $52 \mathrm{IU} / \mathrm{l}$. On last contact with the patient, he reported complete resolution of signs and symptoms, and his liver function tests continued to improve.

\section{Discussion}

A challenge often faced by physicians suspecting DILI is that it is a diagnosis of exclusion. Guidelines from the ACG recommend a stepwise approach. In this case, the patient presented with overt signs of liver injury. Upon reviewing the patient's detailed history, it was discovered that while he was not taking any prescribed medications, he was ingesting 17alpha alkylated androgen compounds daily, along with injectable testosterone weekly for 3 months. There was a clinical suspicion for DILI from the history and presentation alone.

This case illustrates the need for additional tools to aid in the accurate diagnosis of DILI. The algorithm recommended by ACG (fig. 1) begins with obtaining a thorough history. Secondly, the $\mathrm{R}$ value must be calculated. Based on his liver function tests, his calculated $\mathrm{R}$ value 
$<2$ revealed a dominant cholestatic pattern, which coincides with the histopathologic findings discussed below. Alternatively, clinicians may rely on the Roussel Uclaf Causality Assessment Method (RUCAM). This is a tool that is widely used to determine the causality attribution for suspected DILI. However, in comparison to the gold standard of expert consensus, RUCAM has low retest reliability. Though the patient's RUCAM score was 7, indicating a highly probable DILI, additional tools are needed to aid an accurate diagnosis, as RUCAM alone is suboptimal in comparison to the gold standard set in place by the Drug-Induced Liver Injury Network (DILIN) [1]. This patient had moderately severe DILI as evident by his clinical jaundice and hyperbilirubinemia [7]. For this case, the ACG algorithm (fig. 1) was followed to diagnose DILI, which was further supported through liver biopsy findings.

AAS, particularly the 17-alpha alkylated compounds (methyltestosterone, methandrostenolone, oxymetholone, oxandrolone, and stanozolol) have the potential to produce a wide range of hepatic disturbances [8]. The DILIN published a 2014 study in Hepatology demonstrating the most common histopathologic patterns of injury as: inflammation, cholestasis or both, and emphasized the necessity of histological diagnosis for suspected DILI [9]. This case had a pattern of cholestasis and portal inflammation on histology (fig. 2, 3). Newer literature, however, has AAS categorized among the class of agents that produce a primary morphologic change of cholestasis without portal inflammation [5]. The modified hepatic activity index is an assessment designed to grade the severity of hepatic inflammation and ultimately predict patient prognosis [8]. The patient's mild portal inflammation was associated with a modified hepatic activity index score of 1 , which has a more favorable prognosis.

Oral 17-alpha alkylated androgens are a synthetic derivative of testosterone designed to produce increasing anabolic and decreasing androgenic effects while resisting liver degradation. These 17-alpha alkylated compounds have been linked to a higher incidence of hepatotoxicity [10]. Oxandrolone, the compound used by the patient in this particular case report, is FDA approved for the treatment of bone pain associated with osteoporosis, muscle wasting syndromes, and counteracting catabolism associated with long-term corticosteroid use [11]. Oxandrolone is now being advertised on several bodybuilding websites, some of which are recommending doses at $60 \mathrm{mg} /$ day for optimal results. The patient in this case report had been taking $50 \mathrm{mg} /$ day for 3 months prior to experiencing symptoms of acute liver injury.

Proving that an episode of liver injury is caused by a drug is difficult in many cases as it requires the elimination of alternative etiologies. DILI is nearly always a presumptive diagnosis, and many other disorders produce a similar clinicopathologic picture. Thus, causality may be difficult to establish and requires several, separate supportive assessment variables in order to lead to a high level of certainty. Some of the variables include temporal association (time of onset, time to resolution), clinical-biochemical features, type of injury (hepatocellular and/or cholestatic), extrahepatic features, the likelihood that a given agent is the culprit based on its known manifestations with prior cases, and exclusion of other potential causes. This case illustrates the utility of the diagnostic tools used for DILI as recommended by the ACG, along with a supplemental histopathologic diagnosis. With the rise in off-label use of prescription medications, it is important to use guidelines to aid in the diagnosis of DILI. 


\section{Statement of Ethics}

Approval from the local Ethics Committee was not required for this case report. Informed consent was obtained from the patient for publication of this case report.

\section{Disclosure Statement}

All authors have no conflicts of interest to disclose.

\section{References}

1 Chalasani NP, Hayashi PH, Bonkovsky HL, Navarro VJ, Lee WM, Fontana RJ: ACG Clinical Guideline: the diagnosis and management of idiosyncratic drug-induced liver injury. Am J Gastroenterol 2014;109:950-966.

2 Kaplowitz N: Idiosyncratic drug hepatotoxicity. Nat Rev Drug Discov 2005;4:489-498.

-3 Maddur H, Chalasani N: Idiosyncratic drug-induced liver injury: a clinical update. Curr Gastroenterol Rep 2011;13:65-71.

-4 Khashab M, Tector AJ, Kwo PY: Epidemiology of acute liver failure. Curr Gastroenterol Rep 2007;9:6673.

5 Dienstag JL, Isselbacher KJ: Toxic and drug-induced hepatitis; in Kasper DL, Braunwald E, Fauci A, Hauser S, Longo D, Jameson JL (eds): Harrison's Principles of Internal Medicine, ed 19. New York, McGraw-Hill Professional, 2015, chapt 296.

6 Chalasani N, Fontanta FJ, Bonkovsky HL, Watkins PB, Davern T, Serrano J, Yang H, Rochon J: Causes, clinical features, and outcomes from a prospective study of drug-induced liver injury in the United States. Gastroenterology 2008;135:1924-1934.

7 United States National Library of Medicine and the National Institute of Diabetes and Digestive and Kidney Diseases. Roussel Uclaf Causality Assessment Method (RUCAM) in drug-induced liver injury. United States National Library of Medicine Website. http://livertox.nlm.nih.gov/ (retrieved June 20, 2016).

-8 Ishak K, Baptista A, Bianchi L, et al: Histological grading and staging of chronic hepatitis. J Hepatol 1995;22:696-699.

-9 Kleiner DE, Chalasani NP, Lee WM, Fontana RJ, et al: Hepatic histological findings in suspected druginduced liver injury: systematic evaluation and clinical associations. Hepatology 2014;59:661-670.

10 Sánchez-Osorio M, Duarte-Rojo A, Martínez-Benítez B, Torre A, Uribe M: Anabolic-androgenic steroids and liver injury. Liver Int 2008;28:278-282.

11 Oxandrolone tablets USP (package insert). Hunt Valley, Pharmaceuticals International, 2004. 


\section{Case Reports in Gastroenterology}

Case Rep Gastroenterol 2016;10:499-505

(C) 2016 The Author(s). Published by S. Karger AG, Basel www.karger.com/crg

Cabb et al:: The Diagnosis and Manifestations of Liver Injury Secondary to Off-Labe Androgenic Anabolic Steroid Use

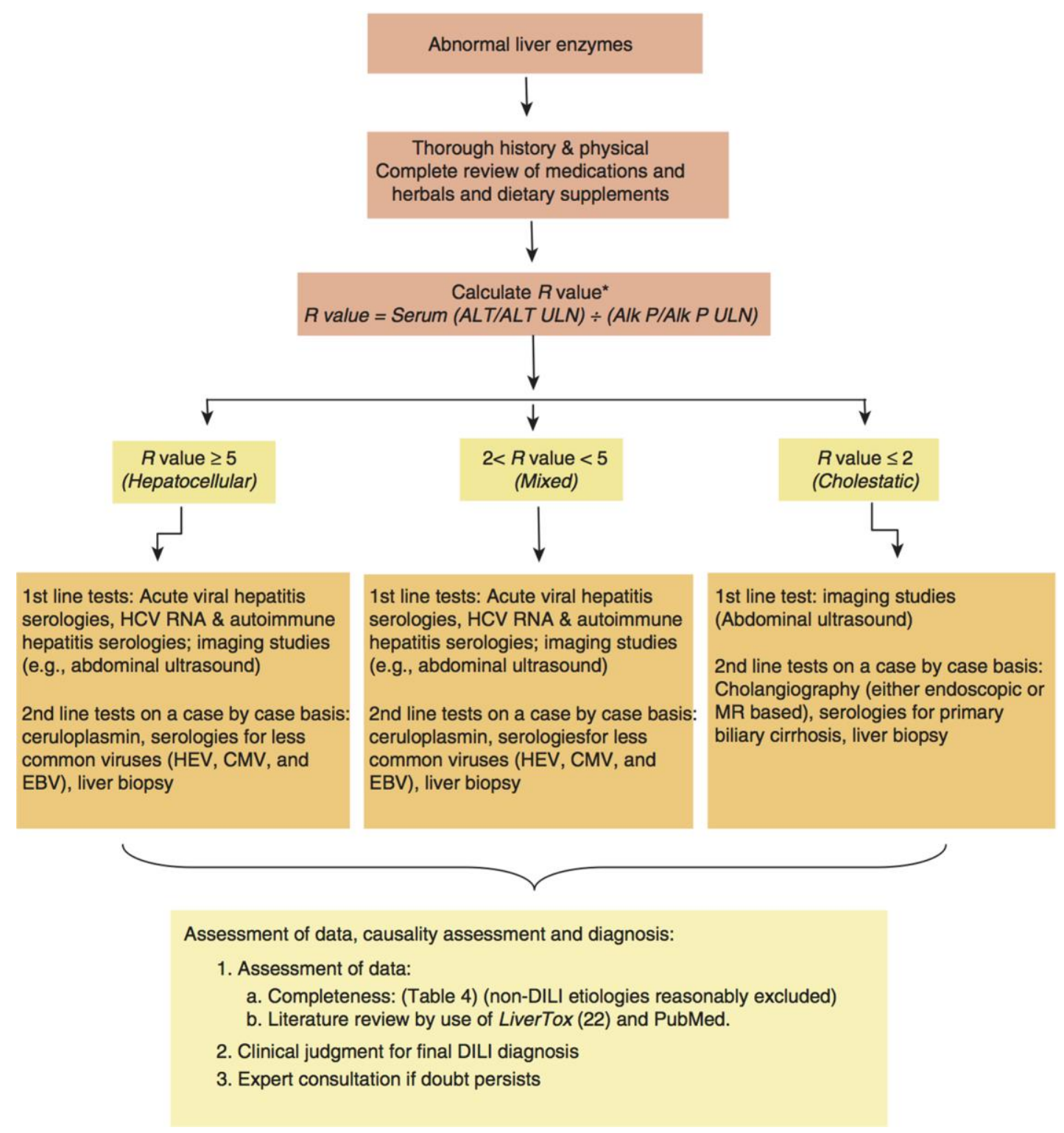

Fig. 1. An algorithm to evaluate suspected idiosyncratic DILI. The R value cutoff numbers of 2 and 5 only serve as a guideline. Tests ordered must be based on the overall clinical picture, including risk factors for competing diagnosis [e.g., recent travel to hepatitis E virus (HEV) endemic area], associated symptoms (e.g., abdominal pain, fever), and timing of laboratory tests (i.e., the $\mathrm{R}$ value may change as the DILI evolves) [1]. ALT = Alanine aminotransferase; Alk P = alkaline phosphatase; $\mathrm{CMV}=$ cytomegalovirus; $\mathrm{EBV}=$ Epstein-Barr virus; $\mathrm{HCV}=$ hepatitis $\mathrm{C}$ virus; $\mathrm{HSV}=$ herpes simplex virus; $\mathrm{MR}=$ magnetic resonance; $\mathrm{ULN}=$ upper limit of normal. 


\section{Case Reports in Gastroenterology

\begin{tabular}{l|l}
\hline Case Rep Gastroenterol 2016;10:499-505 \\
\hline DOI: 10.1159/000448883 & $\begin{array}{l}\text { @ 2016 The Author(s). Published by S. Karger AG, Basel } \\
\text { www.karger.com/crg }\end{array}$ \\
\hline
\end{tabular} \\ Cabb et al.: The Diagnosis and Manifestations of Liver Injury Secondary to Off-Label Androgenic Anabolic Steroid Use}

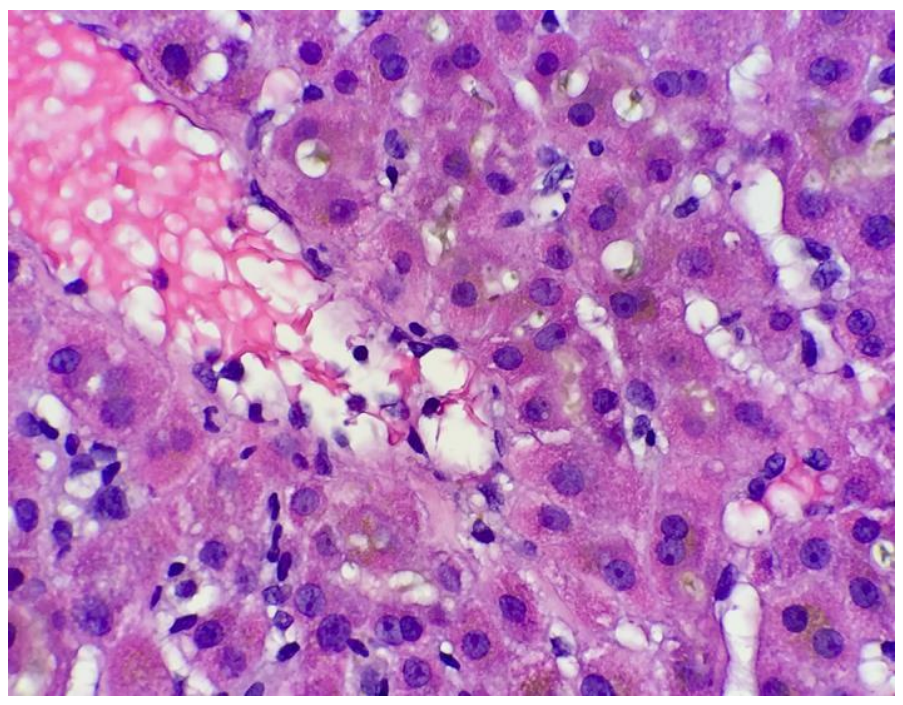

Fig. 2. Centrizonal cholestasis. Red blood cells within the central vein (top left). Bile (olive green) is seen occluding bile canaliculi (white).

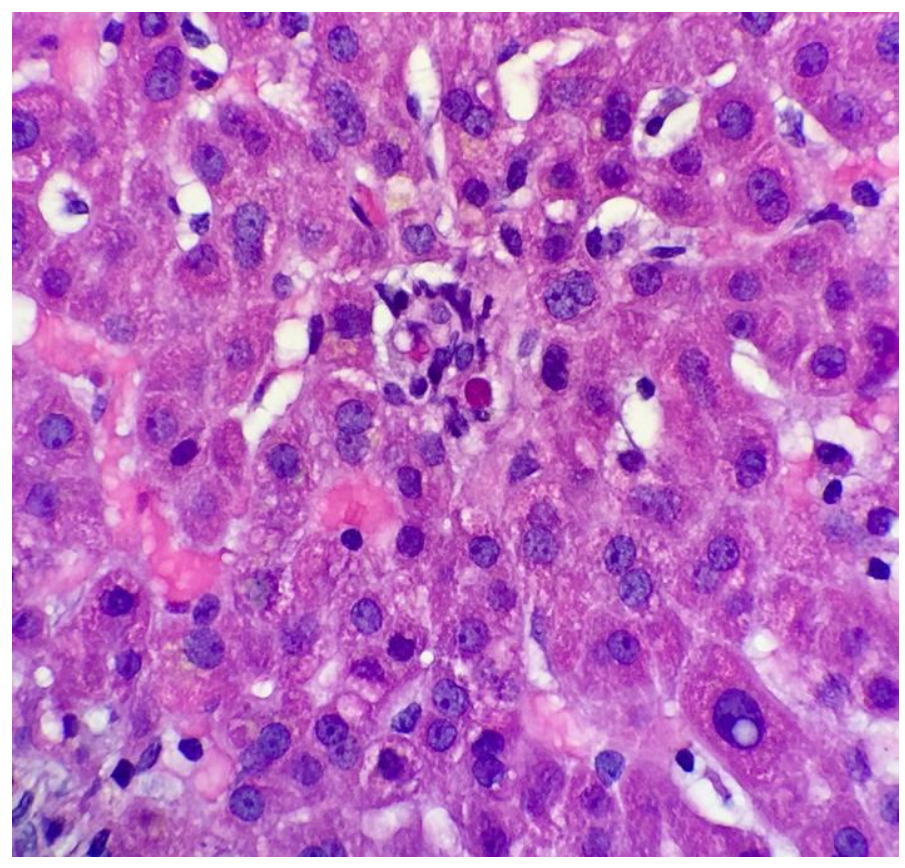

Fig. 3. Focus on lobular injury (spotty necrosis). Dying hepatocyte surrounded by inflammatory cells comprised of lymphocytes and histiocytes. 